Luiz Awazu Pereira da Silva

\title{
How are Central Banks helping to make the Recovery from the Covid-19 Pandemic more sustainable and inclusive?
}

Without the timely, coordinated, countercyclical and massive policy response to the Covid-19 pandemic by fiscal and monetary authorities around the globe, the downturn could have been much worse. On top of their own unprecedented monetary policy response, central banks are facilitating a sustainable and inclusive recovery in many ways. First, by raising awareness that climate-change related risks are a significant threat to global financial stability. Second, by showing that collective coordinated action, changes in supply and demand behaviour, and other public policies including adequate carbon pricing are required. Third, by fostering policies that ensure low financing costs of mitigation and transition and providing guidance that this will be maintained for an appropriately long horizon. Fourth, by developing analytical tools as public goods to improve the measurement, assessment and mitigation of such risks (such as new risk models, climate stress testing, climate scenarios, disclosure of carbon exposures and analysis of the redistributive impact of climate policies). And fifth, by engaging with the financial private sector to develop new financial instruments to accelerate adaptation and transition towards a net zero goal, which is increasingly endorsed by many countries.

For a long time, we believed that there was an infinite supply of natural resources and that their use entailed little to no cost. The consumption of air, water, forests and natural capital in general had very few restrictions and, amid those restrictions, technology would make it possible to use natural resources ad infinitum. Scepticism about "limits to growth" started in the 1970s with concerns about energy consumption from fossil fuels, and by the late 1980s, repeated warnings by climate scientists led to the creation of the Intergovernmental Panel on Climate Change (IPCC), which was established with the support of the UN Environment Programme and the World Meteorological Organization. The link between global warming and human activity - in particular through the emission of greenhouse gases (GHG) - continued to be analysed and gained traction thanks to further research by prominent social scientists. ${ }^{1}$ By the end of the 1990 s and 2000s, the cu-

1 The Stern Review on the Economics of Climate Change, issued on 30 October 2006 by Nicholas Stern, was the first economic report on climate change characterised as the greatest and widest-

Note: The opinions expressed here are those of the author and may not be attributed to BIS.

https://doi.org/10.1515/9783110752892-020 
mulative growing evidence about GHG effects had changed social awareness of the risks related to climate change, the sustainability of the way we produce and consume, and the need for transitional solutions to a less risky, carbon-based economy, for all. Finally, this evolution of mindsets received further support, especially after the Global Financial Crisis, amongst the central banking community ${ }^{2}$.

The reasons for central banks to become involved with climate change had to overcome two extreme viewpoints. On the one hand, by limiting its involvement a central bank was simply respecting its strict explicit mandate and preserving its independence. On the other hand, central banks were summoned to involve themselves even with no explicit mandate since they would be acting on a greater-than-the-Global Financial Crisis "emergency". De facto, many central banks have since pragmatically been addressing many climate issues interpreted within their mandates, while also recognising that there is no silver bullet against global warming and that they alone cannot mitigate all climate change-related risks.

Indeed, the impact of climate change directly undermines the objectives of most central bank mandates. Financial stability is potentially threatened by severe weather events, with massive losses of capital related to physical and transitional climate change-related risks. Moreover, price and macroeconomic stability are affected by climate change-related shocks and uncertainty, including food prices, shortages, mass migration, savings, lower employment and financial crises. Finally, and more importantly, central banks need to take into account rapid changes taking place in the real economy and financial sector. Both are moving faster than the official sector: demand is increasing among investors and consumers for greater commitments to sustainability, transparency and consistency; and the supply of green portfolios is growing, coupled with an evolving taxonomy, a higher volume of green financial assets, and an increased appetite to hold and manage them.

ranging market failure ever. The report had a large public repercussion. In 2005, Jared Diamond published Collapse: how societies choose to fail or succeed, which describes the causes of historical societal collapse, especially as related to the impact of man-made or other environmental changes.

2 In a seminal 2015 speech, "Breaking the tragedy of the horizon - climate change and financial stability", Mark Carney stated that "[c]limate change is the Tragedy of the Horizon" and that "once climate change becomes a defining issue for financial stability, it may already be too late". 


\section{“The green Swan" Contribution to the Debate: It is about Risk!}

The publication The green swan: central banking and financial stability in the age of climate change ${ }^{3}$ tried to move the climate change debate in the financial sector from an ethical to a risk-based discussion. The metaphor was inspired by Nassim Nicholas Taleb's black swans during the Global Financial Crisis - they represented the exceptional and rare nature of a sequence of financial meltdowns that nevertheless created a global financial crisis. A green swan also represents an event, but one that is bound to happen because it is the result of climate change and is therefore, according to today's science, a quasi-certainty. When and in what form the event will take place are unknown. However, in recent years we have seen numerous, glaringly obvious manifestations of these growing risks, including those related to natural weather catastrophes. In addition, cases of zoonosis - which can spark pandemics such as the one our world is currently witnessing - are also the result of the destruction of animals' natural habitat and the loss of biodiversity. The Covid-19 pandemic, which has paralysed the global economy over the last year, serves as a useful illustration of how expected events related to climate change, albeit unfolding at a very slow pace, can materialise suddenly and accelerate dramatically. ${ }^{4}$

The messages in The green swan come directly from today's best science. First, climate change calls for an epistemological rupture in risk models, breaking away from: (i) Gaussian distributions of risk (with fat tails or not); (ii) the linearity of transmissions of climate change-related risks; and (iii) the convenient extrapolation of the consequences of these events using historical data. Second, the best science warns us of: (i) the quasi-certainty of the occurrence of climate change-related catastrophic material and human losses; and (ii) the crossing for our societies of irreversible tipping points if we emit GHGs beyond the 420 billion tonne threshold of $\mathrm{CO}_{2}$ equivalents. Indeed, the latest IPCC reports calculate that this emission budget is the maximum limit (at the $66 \%$ confidence level) for average temperatures on the planet to grow by less than $1.5^{\circ} \mathrm{C}$. In a nutshell, The green swan alerted us to the reality that, given these risks, the "wait-and-see" attitude behind our benign neglect is itself very risky.

3 P Bolton, M Després, L Pereira da Silva, F Samama and R Svartzman, The green swan: central banking and financial stability in the age of climate change, Bank for International Settlements and Banque de France, 2020.

4 See L Pereira da Silva, “Green Swan 2 - climate change and Covid-19: reflections on efficiency versus resilience”, speech based on remarks at the OECD Chief Economist Talk Series, Paris, 23 April 2020 and a research webinar at the BIS, 13 May 2020. 
The green swan highlights that the risk of waiting too long is not worth taking, and that we need to act even in spite of radical uncertainty because climate change-related risks are asymmetrical. That is, we are faced with the quasi-certainty of incurring huge future losses versus paying a small mitigation cost today. Therefore, it is better to prevent risks, to insure against future losses and to build buffers now even in the absence of supportive optimal carbon pricing, better models than our integrated assessment models (IAMs), other models in a general equilibrium framework or even an ideal understanding of all the ramifications of climate change. We also need to act by moving towards financing the transition to a less carbonised economy and thinking about its complex coordination issues. There is no entity within society that can perform this transition by itself, no matter its influence - be it central banks, governments, global banks or private firms. We must work together for the common good - all hands on deck.

\section{How Central Banks are and should continue contributing: Providing public Goods on climate change-related Risks, and Fostering global and local Coordination}

Beyond promoting awareness and building consensus, central banks are providing guiding frameworks for the public and private financial sector and civil society. The Network for Greening the Financial System (NGFS), which regroups the community of central banks and supervisors, has been instrumental in offering such public goods. In addition, public interventions by central bank Governors have been explicit about the importance of climate change for central banks in both advanced and emerging economies. ${ }^{5}$

5 See C Lagarde "Climate change and central banking" keynote speech at the ILF conference on Green Banking and Green Central Banking, Frankfurt, 25 January 2021; L Brainard "Financial Stability Implications of Climate Change”, speech at “Transform Tomorrow Today” Ceres 2021 Conference, Boston, 23 March, 2021; Y Gang "Make full use of China's monetary policy space and promote green finance”, remarks at the Roundtable of China Development Forum, 21 March 2021; H Kuroda “Addressing climate-related financial risks - from a central bank's perspective”, remarks by at the International Research Workshop on Climate-related Financial Risks, Bank of Japan, 25 March 2021; A Bailey “The time to push ahead on tackling climate change”, speech at the Corporation of London Green Horizon Summit, 9 November 2020; F Villeroy de Galhau "Paris 2020 Climate Finance Day" speech at the Paris 2020 Climate Finance Day, Paris, 29 October 2020; J Weidmann "Climate change and central banks", address at the Deutsche Bundesbank's second financial market conference, Frankfurt am Main, 29 October 2019; A Díaz de León "Climate change and its impact on the financial system", remarks at the Conference on Climate Change and its Impact on the Financial System, Mexico City, 5 December 2019; R Campos Neto "BC\# Sustain- 
The central banking community is addressing climate change in five key ways. First, they are continuing to improve analytical tools to assess climate change-related risks and test the resilience of our financial sectors, in particular developing new macro models - beyond IAMs or DSGEs - as well as new risk metrics, climate-related stress tests, and scenarios for $1.5^{\circ} \mathrm{C}$ with sustainable growth for the real economy and financial sector.

Second, central banks are continuing to discuss the scope and role of macroprudential tools and monetary policies, including those for collateral and asset purchase programmes. The Basel Committee, for example, has a task force on climate-related financial risks. These are not trivial issues, and the discussion has to weigh the pros and cons of introducing some form of shadow asset pricing while we still have not been capable of introducing an adequate global real carbon price.

Third, central banks are working on policies for disclosure and accounting standards, together with the Financial Stability Board and its Task Force on Climate-related Financial Disclosures (TCFD), and the International Financial Reporting Standards (IFRS) consultation on sustainability reporting.

Fourth, the central banking community is working to make the taxonomy on green investment products for investors and civil society more consistent, with an emphasis on such things as comparable environmental, social and corporate governance (ESG) criteria and green bond standards.

And finally, the central banking community is seeking a greening of its own assets, such as reserves and pension funds, while offering investment options for investors that favour green finance.

But it doesn't end there. The central banking community is also working to strengthen coordination between local and global agents to avoid free riding and problems arising from collective action, while favouring greater cooperation and helping to find a reasonable balance of burden-sharing for mitigation and adaptation policies. Central banks realise that climate change actions require a significant amount of coordination ${ }^{6}$, especially in the light of governments' commitment to a net zero emissions approach. It requires the involvement of governments, treasuries and fiscal policy to address Pigovian carbon taxes, trading and pricing emissions. It requires international institutions and development banks to

ability Agenda”, presentation at the launching of the Sustainability agenda, Brasília, 8 September 2020.

6 The need to address inclusion, the pandemic and climate change challenges is the priority of the G20 Presidency in 2021 see I Visco “The G20 under Italy's leadership in 2021”, keynote speech at The Global Foundation - Rome Roundtable 2020 "Which way the world after the pandemic? Our inclusive human future”, 16-17 November 2020. 
help leverage the financing costs of transition and mitigation. ${ }^{7}$ Lastly, but equally important, it requires real sector firms, banks, insurance companies, regulators, standard-setters and ratings agencies to ensure consistency with the commitments established.

While recognising the dramatic cost Covid-19 has had on human societies and the global economy, one collateral effect is that the pandemic may have triggered a behavioural change. It showed, overwhelmingly, the evidence of the huge costs of green swans and, amid the pain and suffering, helped relay to societies, policymakers and the private sector the asymmetric risk-return that global warming entails, and the need for immediate action.

\section{The "first-best" Solution of Combating Climate Change faces Redistributive Challenges}

Acting now comes with a warning: there are distributional consequences of climate change policies and for the transition to be successful, the political economy must be considered. The risks and impact of global warming disproportionately affect poor countries and poor households in rich countries. The global and local short-term social effects of mitigation policies might be regressive on impact before the medium- to long-term welfare benefits materialise. Therefore, there is an urgent need to think about and design such policies keeping in mind compensation and transfers, as these are important elements to build support and fairness. This is not specifically a central bank role, but this concern can be present in the overall coordination process with fiscal authorities.

To change relative prices in our economies to favour less carbon-based production and consumption, the textbook solution is to fix a price and internalise the negative externality arising from the emission of GHGs. A carbon price via tax or an emission right is needed, but we now know that it not only presents technical difficulties - such as its transmission to the whole economy - but has a redistributive and therefore also a political impact, particularly because of the diversity of social groups potentially subject to this tax and their uneven capacity to absorb its costs. Any transition to a new carbon regime in a new society has a

7 The coordination with United Nations agencies, eg UNEP, and the Bretton Woods institutions, as well as others, is essential. In November 2020, the first Finance in Common Summit assembled 450 public development banks whose annual total investments total about $\$ 2.3$ trillion, about $10 \%$ of total global investments. The summit aimed at ensuring the recovery from the Covid-19 pandemic is in line with the principles of sustainable finance, the Paris Agreement and a key milestone ahead of the Glasgow Climate Change Conference (COP 26). 
redistributive impact. In theory, changes happen seamlessly, free of adjustment cost and pain, and entail an instant reallocation of resources to different entities and sectors that emit less carbon. But there is de facto a transition cost with highly significant redistributive consequences. These effects must not be overlooked by economic policymakers as they can exacerbate the inequalities within our societies. If we were to implement good climate policies that could increase inequality and social fragility without considering compensation mechanisms, we could inadvertently trigger a backlash. That applies at both the national and international level. For example, the capacity to finance the transition to a lower carbon economy in India, Brazil or Indonesia is not the same as in Norway, Switzerland or France. That means while working on fixing a suitable price for carbon, we must also look at alternatives and use other complementary instruments, which are also required for this transition. That naturally raises the question of financing the transition and, subsequently, the role of finance. It is vital to know how to finance a transition to make it more likely that it will entail, not as many people fear, an economic contraction, but rather an expansion. It's not a minor issue.

Last but not least, while these are mostly issues for fiscal authorities, central banks are increasingly aware of how inequality can influence the effectiveness of their policies. For example, the issues of transmission across different groups and, implicitly, inequality have featured more prominently in major central banks' current reviews of monetary policy. ${ }^{8}$ In practical terms, some central banks are extending their description of the monetary transmission channel to heterogeneous agents and thus are considering the role played by inequality.

\section{Central Banks can enhance the positive Role of the Financial System in the Transition}

For a start, it is vital to make the financial system more resilient in the face of the increasingly massive potential costs of accidents caused by extreme natural catastrophes (storms, hurricanes, forest fires etc). We need to reflect on the capital and other buffers that need to be put in place to face these climate shocks, so as to avoid a new global financial crisis. The central bank community is aware of this, and the pandemic has actually proved that the consolidation work undertaken after the Global Financial Crisis added resilience to the financial sector.

8 See J Powell, “New economic challenges and the Fed's monetary policy review”, in Navigating the decade ahead: implications for monetary policy, proceedings of the Federal Reserve Bank of Kansas City Jackson Hole symposium, August 2020. 
Then, we need to look at how to finance the numerous good ideas that are emerging from many quarters. Obviously, supporting innovation in new technologies (clean energy and climate-related R\&D) is paramount, as is acting and investing in green infrastructure that uses better standards and lower-carbon production processes. ${ }^{9}$

Therefore, we need to develop new financial instruments to help us channel savings and invest them into these new fields and help alter investor behaviour. Green finance is, in general, the route the financial sector is thinking of taking in this transition. This sector is looking at new green instruments because it makes business sense as the demand is there. But the financial system's creativity is also responding to a reputational risk. Some governments, companies and portfolio managers are aware of a behavioural change among consumers and investors, for example in Norway with the sovereign wealth fund, or BlackRock or Amundi. ${ }^{10}$ There is a growing willingness on the part of the entire financial sector to improve the clarity and taxonomy of these new instruments and central banks and regulators are helping to incentivise this process. How exactly can we improve the definition of a green bond? How can we better illustrate and bring together the various concepts behind ESG criteria in a given financial instrument? What are the implications of the risks and returns of investing in such a product? These new demands can improve investor behaviour and the way in which certain financial institutions present these products to finance a transition. When we put all this together, we are assembling the various pieces of what could later be a consistent new macroeconomic policy for addressing climate change.

9 Chapter 11 of Bill Gates' How to avoid a climate disaster (2021) provides an extensive list of practical ideas and suggestions with related institutional changes.

10 Regarding governments, 113 countries have committed to be mostly carbon-neutral by 2050, representing about $50 \%$ of world GDP, and nine have set legally binding targets. Among asset owners, \$5.1 trillion is committed through the Net-Zero Asset Owner Alliance, and among asset managers, \$9 trillion is committed through the Net Zero Asset Managers Initiative. In June 2019, Norway's sovereign wealth fund (managing $\$ 1$ trillion in assets) signalled a gradual fossil fuel divestment policy. In his annual letter to CEOs on 14 January 2020, BlackRock's Larry Fink said: "Climate change has become a defining factor in companies' long-term prospects ... awareness is rapidly changing, and I believe we are on the edge of a fundamental reshaping of finance." BlackRock's assets under management are around \$7 trillion. In Europe, at Amundi (about \$1.7 trillion under management), Frédéric Samama has been instrumental in the Portfolio Decarbonisation Coalition, the creation of low-carbon indices, and one of the world's biggest green bond funds. 


\section{Conclusions: Never "waste a Crisis". Use the Covid-19 Crisis as an Opportunity to aim at sustainable and more inclusive Recovery}

Central banks have been acting in significantly to mitigate the pandemic's devastating effects. They have also coordinated with other actors, as mentioned above. They have been contributing to promote new ideas for green finance. Why is this transition so critical, and why is it important to find the means to finance it? ${ }^{11}$ My short answer is because it will increase the likelihood of an expansionist outcome that, in turn, will help overcome the political economy and redistributive challenges alluded to earlier. Figure 1 shows a hypothetical example of the opportunities the Covid-19 crisis can offer.

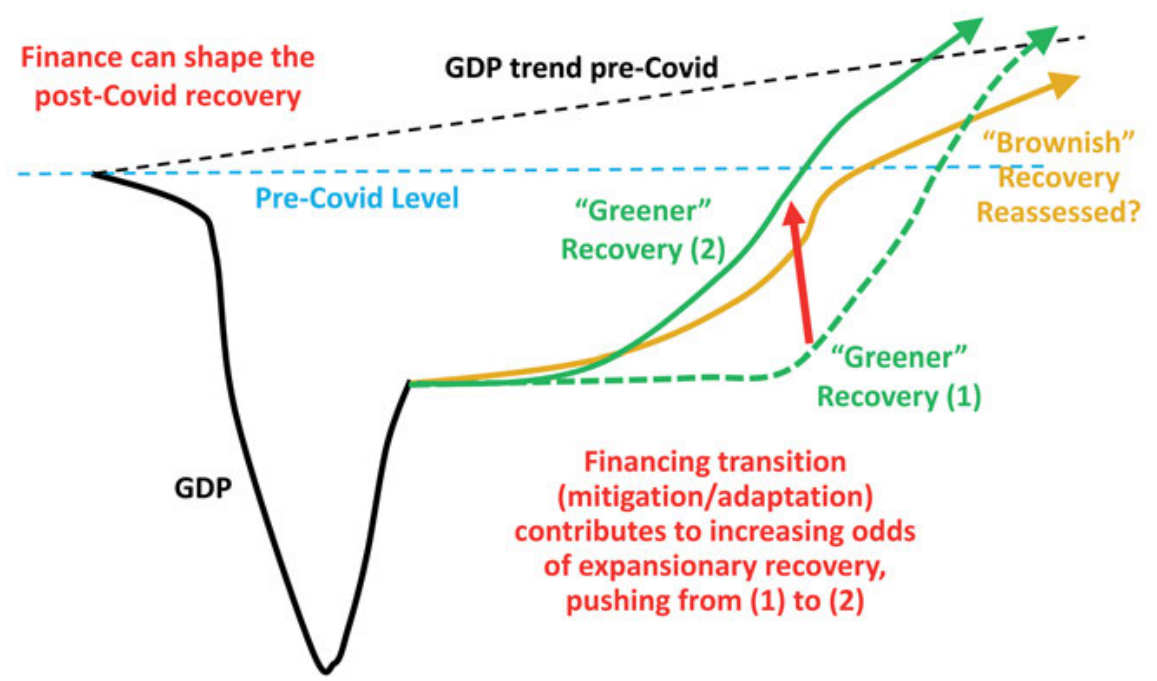

Figure 1: Post-Covid recovery: the role of green finance

As we already know, the Covid-19 pandemic made global GDP growth (solid black line in the stylized figure 1 above) fall dramatically. In an uneven way in many countries, we are beginning to witness a V-shaped recovery, or rather a "square

11 See K Georgieva (IMF Managing Director), "Securing a green recovery: the economic benefits from tackling climate change”, remarks at the PBC-IMF High-Level Seminar on Green Finance and Climate Policy, 15 April 2021; and F Elderson (NGFS Chair), “A green light to lead us on the path of economic recovery”, remarks at the 11th edition of the Petersberg Climate Dialogue: Financing Climate Ambition in the context of Covid-19, 29 April 2020. 
root”, as activity levels have yet to return to pre-Covid levels ${ }^{12}$. What type of recovery can we expect from now? Could it combine a rebound in activity, job creation and a greener economy? At first glance, this crisis is so severe that it would be better not to set extra goals and instead accept a more "brown" recovery, with an upturn based on the traditional instruments and technologies that stimulate employment and economic activity. A recovery powered in part by green investment is represented by the green dotted line: it would be slower as it would take longer to mobilise the technologies that are slightly more expensive. This figure, admittedly rudimentary and simplistic and which is not a forecast, illustrates how more green finance (with debt and equity) in the transition with more green technologies can hasten the availability and impact of new technological solutions. ${ }^{13}$ Green financing instruments for investment in innovation and more risk-taking may offer the possibility to increase the pace of the recovery, substitute our existing capital stock faster, incentivise shifts in consumption and push it higher, to that solid green line, which would enable a recovery trajectory that would be quicker over the medium term than the traditional recovery fuelled by the type of consumption and production we had pre-Covid. The challenge is to use the current crisis as an opportunity to accelerate the transformation of our societies using new instruments to finance innovation, a kind of Schumpeterian creative destruction. ${ }^{14}$ And indeed, in 2021 this is being implemented in the United States and Europe, with bold action being taken aiming at both sustainability and more inclusion. ${ }^{15}$

Is that path totally unrealistic? No, it isn't. If we move from a macroeconomic to a project perspective, a study by Nick Stern and Joseph Stiglitz ${ }^{16}$ compares the different public policy measures that can be implemented to boost a recovery, for example research, infrastructure investments etc. Figure 2 shows the growth ac-

12 See IMF World Economic Outlook: Managing Divergent Recoveries, April 2021.

13 A more sober but still supportive view is J Pisani-Ferry, "A credible decarbonization agenda can help strengthen Europe’s economy”, PIIE, 9 December 2019.

14 This is the point made in P Aghion, C Antonin and S Bunel, "Innovation verte et croissance soutenable”, in Le pouvoir de la destruction créatrice, 2020.

15 The European Green Deal is a multi-year package of at least $€ 1$ trillion in investment as a strategy committing to zero net emissions of greenhouse gases by 2050, betting on turning climate and environmental challenges into opportunities, and making the transition just and inclusive for all. The Biden infrastructure plan is a $\$ 2$ trillion plan to overhaul and upgrade US infrastructure while taking into account climate risk and resilience. In addition US Treasury Secretary Janet Yellen reaffirmed President Biden's \$1.9 trillion coronavirus relief package: "it's the right size to address the very significant problem that we have"; see J Yellen, ABC news interview by J Arnholz, 14 March 2021.

16 C Hepburn, B O'Callaghan, N Stern, J Stiglitz and D Zenghelis, "Will Covid-19 fiscal recovery packages accelerate or retard progress on climate change?”, Oxford Review of Economic Policy, volume 36, number S1, May 2020. 
tivity multipliers on the horizontal axis to the right, and the impact of the reduction in negative climatic effects on the vertical axis.

\section{Multipliers and climate impact of a "green" recovery according to experts}

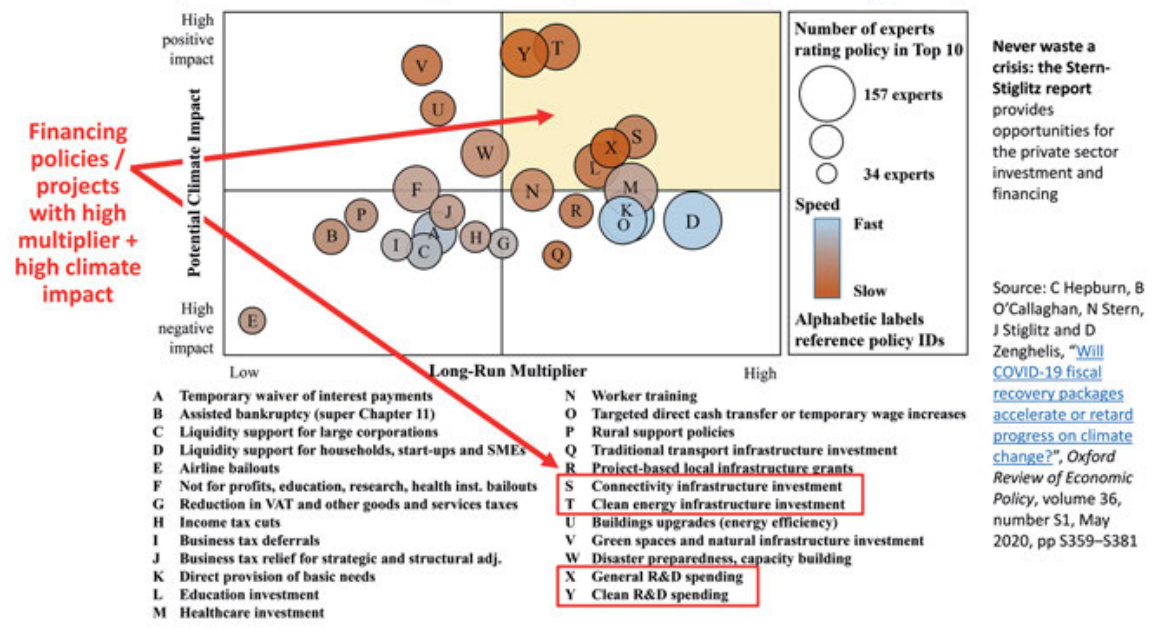

Figure 2: Possible projects for a green recovery

Different economic policy measures and eligible projects are points on this diagram, and we ideally would like these measures to be in the upper-right quadrant, where the projects have a strong impact on activity (high budgetary multiplier) and a strong mitigating impact on climate risk. The study provides at least four good examples of that: greener infrastructure, the search for alternative energies, research and development led by the private sector but also by the public sector, and connectivity and virtual infrastructure.

That means there are projects for relaunching the economy and, at the same time, carefully choosing the effects of this relaunch from the perspective of a transition and fighting climate change. Therefore, having the debt and equity financing for these projects is key since most of these new endeavours will represent a higher risk. The private financial sector has a role to play, but green R\&D innovation will also require a longer-term return horizon that the public sector can provide and the coordination of all these actions. This coordination must include governments, regulators, international organisations and central banks. It is indispensable, not only on the supply side, ie technology, including financial technology, but also on the demand side, meaning the behaviour of each one of us. What will each of us consume and how will we receive price signals and information that will enable us to adjust our consumption to the low-carbon option? 
The Covid-19 pandemic has produced the unprecedented contraction that we long feared with the consequences of physical and transition risks related to climate change. So what is the lesson? It's simple: never waste a crisis. The macroeconomic conditions are favourable. For example, interest rates are low at the moment, savings are higher in many rich countries, demand and awareness is increasing for green products, and there is growing ambition in the United States, European Union, China etc. There are also a number of projects, such as those involving green infrastructure, greener cities, carbon footprint tracing, new technologies and new ways to act using social networks. On the demand side, consumer information and incentives favour a lower-carbon economy and are increasingly aligned. For example, public awareness has risen to allow progress on carbon pricing, GHG emission taxation and emission certificates etc. On the supply side, green finance investors are asking for practical diversification for their portfolios and more projects to lower carbon content and finance the transition. There is more green research and $\mathrm{R} \& \mathrm{D}$, and new technologies emerging, such as carbon capture.

Conditions seem to be emerging for an expansionary, green and more inclusive recovery, and central banks have played an important role in shaping them. Today, due to the Covid-19 crisis, the urgency is to finance an expansionary, sustainable and inclusive transition, find the good instruments and the best interlocutors, and coordinate and act in a way that actually reverses and stops the current trend of $\mathrm{CO}_{2}$ emissions. However, as a final point, we also have to change the way we think and we measure our performances. If natural capital is not free, we must innovate and change, from our national accounts to our models, and analyse the effects of climate on our economies. How can we measure the utilisation and depreciation of natural resources? How could we also value our activity with other metrics beyond market prices ${ }^{17}$ How can we better understand the risk in our models connecting the macroeconomy with the climate in measuring happiness and our wealth ${ }^{18}$ We need to use our time well, because time is not on our side. The pandemic has served as a glaring warning that we don't have eternity before us, that we really are living on borrowed time, and that we need to act decisively to put in place measures that can mitigate the catastrophic risks of global warming.

17 This is the key question that, after pioneering work in alerting the central banking community about climate change, Mark Carney asks in Value(s): building a better world for all (2021).

18 This change will occur through dialogue between macroeconomists and scientists specialising in climate change. The best models we have for transitions are the Nobel Prize-winning contributions by William Nordhaus, for example the IAMs. We also have to place more emphasis on research on new frontiers where we take disequilibrium into account, non-linear trajectories, cascade and amplifying effects, slightly reminiscent of the Mandelbrot set. 